$=10 \%$; DRB103 no found). NAJ ( $p<0.01)$, RS $(\mathrm{p}<0.001)$ and ESR $(p<0.01)$ were higher in EOA than in non-EOA. No differences were observed (ANOVA test) in NAJ, NEJ, RS, ESR and CRP, among the various HLA antigens found in EOA.

Conclusion EOA seems characterised by a high frequency, higher than in non-EOA, of some HLA antigens, in particular DRB103 and DRB1011, thus suggesting an immunogenetic predisposition in these patients. HLA antigens do not seem to be associated with the disease severity of EOA. However, more information may derive from an adequately long follow-up of these patients.

\section{OP0051 SYNOVITIS PREDICTS THE ARTHROSCOPIC PROGRESSION OF MEDIAL TIBIOFEMORAL KNEE OSTEOARTHRITIS (OA)}

${ }^{1} \mathrm{X}$ Ayral, ${ }^{2} \mathrm{EH}$ Pickering, ${ }^{2} \mathrm{TG}$ Woodworth, ${ }^{3} \mathrm{~N}$ Mackillop, ${ }^{2} \mathrm{~L}$ Loose, ${ }^{1} \mathrm{M}$ Dougados. ${ }^{1}$ Rheumatology B, Cochin Hospital, Paris, France; ${ }^{2} R \& D$ Global, Pfizer, Groton, USA; ${ }^{3} R \& D$ Global, Pfizer, Sandwich, UK

\subsection{6/annrheumdis-2001.418}

\section{Background}

Objectives To evaluate the prevalence of synovitis in painful medial tibiofemoral knee OA and to evaluate correlations between such synovitis and the structural severity of medial knee OA.

Methods Multicenter, prospective, one year duration study; primary painful knee OA (ACR criteria) of the medial compartment; medial joint space width $>$ or $=2 \mathrm{~mm}$; at least $10 \%$ of one cartilage surface of the medial compartment affected by superficial fibrillation or worse. Arthroscopy under local anaesthesia performed and videorecorded at entry and after one year; medial chondropathy scored by using SFA score $(0-100)$ and reader's overall assessment (VAS score $100 \mathrm{~mm}$ ); medial perimeniscal synovial scored as normal (few villi, fine vascular network), reactive (proliferation of opaque villi), inflammatory (hypervascularization and/or proliferation of hypertrophic and hyperemic villi). Progression of medial chondropathy defined by an increase in SFA and VAS scores of at least 4.5 and 8.0 after one year, respectively, as previously reported; ${ }^{1}$ assessment of severity of chondropathy by a single reader blind to chronology of paired videotapes.

Results 506 patients were enrolled and 498 completed the one year longitudinal study (mean age: $61.2 \pm 7.7$ years, female sex: 58.9\%, BMI: $30.4 \pm 4.7$, mean disease duration: $3.8 \pm 2.9$ years). The Table 1 summarises cross-sectional and longitudinal correlations between synovitis and chondropathy.

Conclusion This study suggests that synovitis is a common feature of painful knee OA, associated with more severe

\begin{tabular}{llll} 
Abstract OP0051 Table 1 & \\
\hline & $\begin{array}{l}\text { Medial perimeniscal } \\
\text { Normal }\end{array}$ & $\begin{array}{l}\text { Synovial membrane } \\
\text { Reactive }\end{array}$ & $\begin{array}{l}\text { At baseline } \\
\text { Inflammatory }\end{array}$ \\
\hline BASELINE & $\mathrm{N}=252$ & $\mathrm{~N}=145$ & $\mathrm{~N}=109$ \\
SFA score & $30 \pm 19$ & $38 \pm 20^{*}$ & $41 \pm 18^{*}$ \\
VAS score & $34 \pm 17$ & $41 \pm 19^{*}$ & $44 \pm 17^{*}$ \\
CHANGES & $\mathrm{N}=251$ & $\mathrm{~N}=144$ & $\mathrm{~N}=103$ \\
$\%$ SFA progressors & $13.1 \%$ & $14.6 \%$ & $23.3 \%^{* *}$ \\
\% VAS progressors & $13.9 \%$ & $13.2 \%$ & $30.1 \%^{* * *}$ \\
\hline
\end{tabular}

$p$-value vs Normal: ${ }^{*} p<$ or $=0.0003{ }^{* *} p=0.02{ }^{* * *} p=0.0005$. chondropathy, but it also suggests that synovitis could be considered as a predictive factor of subsequent chondrolysis.

\section{REFERENCE}

1 Ayral $X$, et al. Arthroscopic evaluation of chondropathy in osteoarthritis of the knee. J Rheumatol. 1996;23:698-706

\section{OP0052 GLUCOSAMINE SULFATE AS AN OSTEOARTHRITIS DISEASE MODIFICATION AGENT: A CONFIRMATORY, LONG-TERM, RANDOMISED, PLACEBO-CONTROLLED, INDIPENDENT STUDY}

${ }^{1} \mathrm{~K}$ Pavelka, ${ }^{1} \mathrm{~J}$ Gatterova, ${ }^{1} \mathrm{M}$ Olejarova, ${ }^{1} \mathrm{~S}$ Machacek, ${ }^{2} \mathrm{C}$ Gonzalez, ${ }^{2} \mathrm{G}$ Giacovelli, ${ }^{2}$ LC Rovati. 'Institute of Rheumatology, Prague, Czech Republic; ${ }^{2}$ Rotta Research Lab. S.p. A., Monza, Italy

\subsection{6/annrheumdis-2001.419}

Background Recent data showed that glucosamine sulfate is an osteoarthritis disease modifying agent. ${ }^{1}$ International guide-lines on clinical development of osteoarthritis drugs recommend to perform at least two independent studies to confirm the drug properties.

Objectives To confirm the effects of glucosamine sulfate as a disease modifying agent.

Methods Randomised, double-blind, placebo-controlled, study. 202 patients with knee-osteoarthritis (ACR criteria) were randomised to glucosamine sulfate $1500 \mathrm{mg}$ once-a-day p.o., or placebo for 3 years. The minimum joint space width (JSW) of the narrowest medial compartment of the tibio-femoral joint at 3 years was the study structure primary endpoint, and a secondary endpoint at 1 and 2 years. JSW was measured visually by a 0.1 $\mathrm{mm}$ graduated magnifying glass, on standardised weight-bearing antero-posterior radiographs of each knee, in full extension. Symptoms were assessed by both the WOMAC LK 3.0 version and the Lequesne indices.

Results The two study groups were comparable for demographic and disease characteristics and represented the standard primaryknee-osteoarthritis population. The placebo group presented a progressive joint space narrowing (JSN) at each year of evaluation, while glucosamine sulfate presented no average JSN at any point of evaluation. Results at 3 years are shown in the Table 1 below. Glucosamine sulfate significantly improved symptoms as measured by both the Lequesne: $(20-25 \%$ vs. $<10 \%$ with placebo) and the WOMAC (15-20\% vs. <2\%) indices. No significant differences were seen in the reported adverse events rate, while more patients on the placebo group prematurely left the study, without reaching a statistical significance.

\section{Abstract 0P0052 Table 1}

\begin{tabular}{lll}
\hline & $\begin{array}{l}\text { Placebo } \\
(\mathrm{N}=101)\end{array}$ & $\begin{array}{l}\text { Glucosamine Sulfate } \\
(\mathrm{N}=101)\end{array}$ \\
\hline JSW enrolment $(\mathrm{mm})$ & $3.59(0.16)$ & $3.97(0.14)$ \\
JSN 3 years $(\mathrm{mm})$ & $-0.19(0.05)$ & $+0.02(0.05)^{* *}$ \\
Lequesne enrolment (points) & $8.9(0.2)$ & $9.0(0.2)$ \\
$\Delta$ 3 years (points) & $-0.8(0.2)$ & $-1.7(0.2)^{* *}$ \\
WOMAC enrolment points & $30.5(1.4)$ & $30.7(1.4)$ \\
$\Delta$ 3 years (points) & $-4.9(0.8)$ & $-8.0(0.9)^{*}$ \\
\hline
\end{tabular}

Data are mean (SE). ${ }^{*} p<0.05$ and ${ }^{* *} p<0.005$ vs. placebo. Intention-to-treat (ITT) population. 
Conclusion This independent-confirmatory study demonstrated that glucosamine sulfate can be postulated as the first osteoarthritis structure modifying agent. Glucosamine sulfate also improved the disease symptoms in the long-term treatment of the disease, with a safety profile similar to placebo. The action of glucosamine sulfate on both the structure and the symptoms evolution of the disease postulate it as the first osteoarthritis modifying agent.

\section{REFERENCE}

1 Lancet 2001;357:251-6

\section{OP0053 SUCCESS-1 IN OSTEOARTHRITIS (OA) TRIAL: CELECOXIB SIGNIFICANTLY REDUCES RISK OF SERIOUS UPPER GI COMPLICATIONS COMPARED TO NSAIDS WHILE PROVIDING SIMILAR EFFICACY IN 13,274 RANDOMISED PATIENTS}

${ }^{1} \mathrm{G}$ Singh, ${ }^{2} \mathrm{~J}$ Goldstein, ${ }^{3} \mathrm{~W}$ Bensen, ${ }^{4} \mathrm{~N}$ Agrawal, ${ }^{5} \mathrm{G}$ Eisen, ${ }^{6} \mathrm{~J}$ Fort, ${ }^{6} \mathrm{~A}$ Bello, ${ }^{6} \mathrm{~S}$ Boots. ${ }^{1}$ Department of Medicine, Stanford University, Palo Alto; ${ }^{2}$ University of Illinois at Chicago, Chicago; ${ }^{3}$ McMaster University/St. Joseph's Hospital, Hamilton, Canada; ${ }^{4}$ Duke University, Durham; ${ }^{5}$ Vanderbilt University of Medicine, Nashville; ${ }^{6}$ Pharmacia, Peapack, USA

\subsection{6/annrheumdis-2001.420}

Background SUCCESS-1, the largest double-blind, randomised study in rheumatology, compared 2 therapeutic doses of celecoxib to conventional doses of NSAIDs in a trial designed to closely parallel clinical practice in various worldwide settings. Objectives To compare the efficacy, safety, and tolerability of celecoxib 200 or $400 \mathrm{mg} / \mathrm{d}$ and NSAIDs in OA of the knee, hip, and hand.

Methods SUCCESS-1 enrolled 13,274 patients with OA from 1142 centres in 39 countries. Patients were randomised to: celecoxib $200 \mathrm{mg} / \mathrm{d}$, celecoxib $400 \mathrm{mg} / \mathrm{d}$, or NSAID (naproxen 100 $\mathrm{mg} / \mathrm{d}$ in US/Canada, diclofenac $100 \mathrm{mg} / \mathrm{d}$ in other 37 countries). Efficacy assessments, stratified by country/subregion, included patient and physician global assessments, pain scale, night pain, and WOMAC. An independent Gastrointestinal Events Committee (GEC) categorised potential clinically significant upper GI (UGI) events in a blinded fashion as ulcer complications (perforations, gastric outlet obstruction, bleeding) or symptomatic ulcerations.

Results Of 13,194 patients treated, 4393 and 4407 received 200 or $400 \mathrm{mg} / \mathrm{d}$ of celecoxib, respectively, 905 received naproxen $1000 \mathrm{mg} / \mathrm{d}$, and 3489 received diclofenac $100 \mathrm{mg} / \mathrm{d}$. Most patients were female (67\%); mean age was 62 years. Baseline aspirin use and UGI bleeding history were comparable. Efficacy results between the 2 celecoxib doses and naproxen or diclofenac were comparable for most countries/subregions. UGI events (dyspepsia, abdominal pain, and nausea) were significantly reduced in celecoxib- compared to naproxen- or diclofenactreated patients. Of 144 possible serious UGI GEC-referred events, 9 met strict ulcer complication definition and 36 patients had confirmed ulcer complications and/or symptomatic ulcers.

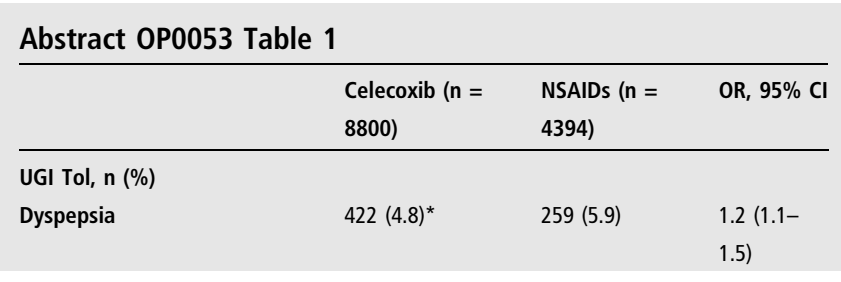

\begin{tabular}{|c|c|c|c|}
\hline Abdominal pain & $423(4.8)^{*}$ & $274(6.2)$ & $\begin{array}{l}1.3(1.1- \\
1.5)\end{array}$ \\
\hline Nausea & $207(2.4)^{*}$ & $151(3.4)$ & $\begin{array}{l}1.5(1.2- \\
1.8)\end{array}$ \\
\hline \multicolumn{4}{|l|}{$\begin{array}{l}\text { Serious GI events, n (inc/100 pt } \\
\text { yrs) }\end{array}$} \\
\hline Possible events? & $83(4.8)$ & $61(7.1)$ & $\begin{array}{l}1.5(1.1- \\
2.1)\end{array}$ \\
\hline Ulcer complics? & $2(0.1)^{*}$ & $7(0.8)$ & $\begin{array}{l}7.0(1.5- \\
33.8)\end{array}$ \\
\hline Symptomatic ulcer/complics? & $18(1.0)^{*}$ & $18(2.1)$ & $\begin{array}{l}2.0(1.0- \\
3.8)\end{array}$ \\
\hline
\end{tabular}

Conclusion Compared to conventional NSAIDs, celecoxib reduced the risk of ulcer complications by almost $87.5 \%$, while providing equivalent efficacy and better tolerability. Sponsored by Pharmacia Corporation and Pfizer Inc.

\section{OP0133 CARDIOVASCULAR SAFETY PROFILE OF ROFECOXIB: A META-ANALYSIS}

${ }^{1}$ DR Shapiro, ${ }^{2} E$ Barr, ${ }^{2}$ AS Reicin. ${ }^{1}$ Biostatistics; ${ }^{2}$ Clinical Research, Merck \& Co., Inc., Rahway, USA

\subsection{6/annrheumdis-2001.421}

Background COX-1 inhibition compromises GI homeostasis; however, by inhibiting platelet aggregation, COX-1 blockade is cardioprotective. COX-2 inhibitor therapy results in marked reductions in GI events relative to non-selective NSAID (COX-1/ COX-2 inhibitor) therapy. Because COX-2 inhibitors do not have antiplatelet properties, chronic use of COX-2 inhibitors or non-selective NSAIDs may result in differential risks of plateletmediated vascular events. Evaluation of the impact of these agents on vascular events is complicated by the variable effects of NSAIDs on platelet aggregation. NSAIDs that mediate near complete inhibition of platelet function throughout their entire dosing cycle may be similar to aspirin and reduce the risk of vascular events; other compounds with less substantial platelet inhibition may have no impact on vascular events.

Objectives To evaluate the cardiovascular (CV) safety profile of rofecoxib, a selective COX-2 inhibitor.

Methods A meta-analysis of all Phase IIb-V clinical trials was conducted using individual patient data and focusing on the relative risk of $\mathrm{CV}$ thrombotic serious adverse experiences in patients taking rofecoxib as compared to placebo, naproxen (an NSAID with near complete inhibition of platelet function throughout its dosing interval), and non-selective NSAIDs that lack potent sustained inhibition of platelet function (diclofenac, ibuprofen, and nabumetone). The primary metric utilised was the Antiplatelet Trialists' Collaboration (APTC) combined endpoint of cardiovascular or unknown death, stroke, or myocardial infarction.

Results Over 28,000 patients in 19 studies (Osteoarthritis, Rheumatoid Arthritis, Alzheimer's, and Chronic Low Back Pain trials) representing over 14,000 patient-years at risk were included in the meta-analysis. The relative risk $(95 \% \mathrm{CI})$ for an APTC combined endpoint was: $0.59(0.37,0.94)$ when comparing naproxen $(\mathrm{n}=7870)$ vs. rofecoxib $(\mathrm{n}=9083) ; 1.27(0.64,2.50)$ when comparing non-naproxen NSAIDs $(\mathrm{n}=2755)$ vs. rofecoxib ( $\mathrm{n}=4549) ; 1.19(0.73,1.96)$ when comparing placebo (n 